\title{
Prevalence of incomplete interlobar fissures of the lung
}

\author{
Zuzana Sedlackova, Filip Ctvrtlik, Miroslav Herman
}

\begin{abstract}
Background. Some patients benefit from accurate integrity assessment of pulmonary fissures. There are a number of methods for the assessment of incomplete interlobar fissures: imaging techniques, endobronchial methods measuring collateral air flow, a perioperative view, and autopsies used in research into pulmonary anatomy.

Methods and Results. We performed a computerized advanced search for primary evidence in the PubMed (Public/ Publisher MEDLINE) and Google Scholar electronic databases using the following terms: incomplete and fissure. The search was not restricted to the English literature, nor limited by publication time. The bibliographic search was then extended to the "Related Articles" links and to the list of literature references of each article.

Conclusion. Publications have consistently shown that interlobar fissures exhibit high variability and that preoperative or at least detailed perioperative assessment can influence the effect of treatment.
\end{abstract}

Key words: pleura, interlobar fissure, incomplete, computed tomography

Received: May 31, 2016; Accepted with revision: September 21, 2016; Available online: October 26, 2016 http://dx.doi.org/10.5507/bp.2016.049

Department of Radiology, Faculty of Medicine and Dentistry, Palacky University Olomouc and University Hospital Olomouc, Czech Republic Corresponding author: Filip Ctvrtlik, e-mail: filip.ctvrtlik@fnol.cz

\section{INTRODUCTION}

Pulmonary interlobar fissures are formed by the visceral pleura and they separate the lung lobes from each other. They enable uniform expansion during breathing. Most of the population has an oblique fissure on both sides and a horizontal fissure on the right-hand side. The position of the fissures exhibits high variability; for example, supernumerary accessory fissures can be encountered and sometimes a fissure is missing completely (usually the horizontal one). Very frequently, only a part of a fissure is missing - mostly in the hilar region (Fig. 1).

Interlobar fissures are used in anatomical resections of the lung lobes and can affect the spread of fluid or infection ${ }^{1,2}$. Thus a radiologist can explain some atypical images on chest X-rays or CT scans ${ }^{3,4}$. When lobectomy is performed in a patient with an incomplete interlobar fissure, there is a higher risk of air leakage ${ }^{2,4-7}$. Incomplete interlobar fissures can also lead to an inadequate result of one of the possible therapeutic approaches in emphysema - the implantation of one-way valves in these patients does not lead to complete lobar atelectasis as a result of collateral ventilation and the effect of the therapy is not optimal ${ }^{8-10}$. On the other hand, the very same condition prevents atelectasis after obstruction of the bronchus by mucus impaction, a tumour or foreign bodies ${ }^{8}$.

There are several possibilities for assessing fissures: imaging techniques, currently preferred is CT (HRCT or MDCT); endobronchial systems assessing collateral flow; perioperative methods and autopsies. On thin slices of CT, the fissure can be seen as a thin line separating the lobes; in the case of incompleteness, the line is disconnected by vessels or the lung parenchyma. Endobronchial methods use a catheter with a balloon component that blocks an airway after inflation. Several techniques can be employed to measure collateral ventilation. The inert gas technique was an older method in which helium was inhaled and its content in a blocked area measured with a mass spectrometer. Afterwards, forced constant airflow going through a double-lumen catheter was used. However, particularly in patients with severe emphysema, this method can lead to barotrauma; therefore, systems operating with spontaneous airflow are currently used ${ }^{11}$. Perioperative mapping is limited by the surgeon's area of interest and is only performed in patients with serious pulmonary disease. In autopsy, well-separated lobes can be detached from one another, while "bridges" between lobes prevent this. An obvious drawback of this method is that it can only be performed on eviscerated lungs.

\section{LITERATURE SEARCH METHODS}

We performed a computerized advanced search for primary evidence in the PubMed (Public/Publisher MEDLINE) and Google Scholar electronic databases using the following terms: incomplete and fissure. The search was not restricted to the English literature, nor limited by publication time. The bibliographic search was then extended to the 'Related Articles' links and to the list of literature references of each article. Using this approach, 31 original articles describing the assessment of incomplete fissures were found (of which 13 used CT only, 2 compared perioperative and CT findings, 3 compared CT with endobronchial measurement of collateral ventilation, and 13 were based on autopsies).

\section{PREVALENCE OF INCOMPLETE FISSURES}

The frequencies of incompleteness obtained by different techniques are summarized in Tables 1-3. For assessment on CT, the authors usually state criteria for incomplete fissures, with several using four types accord- 

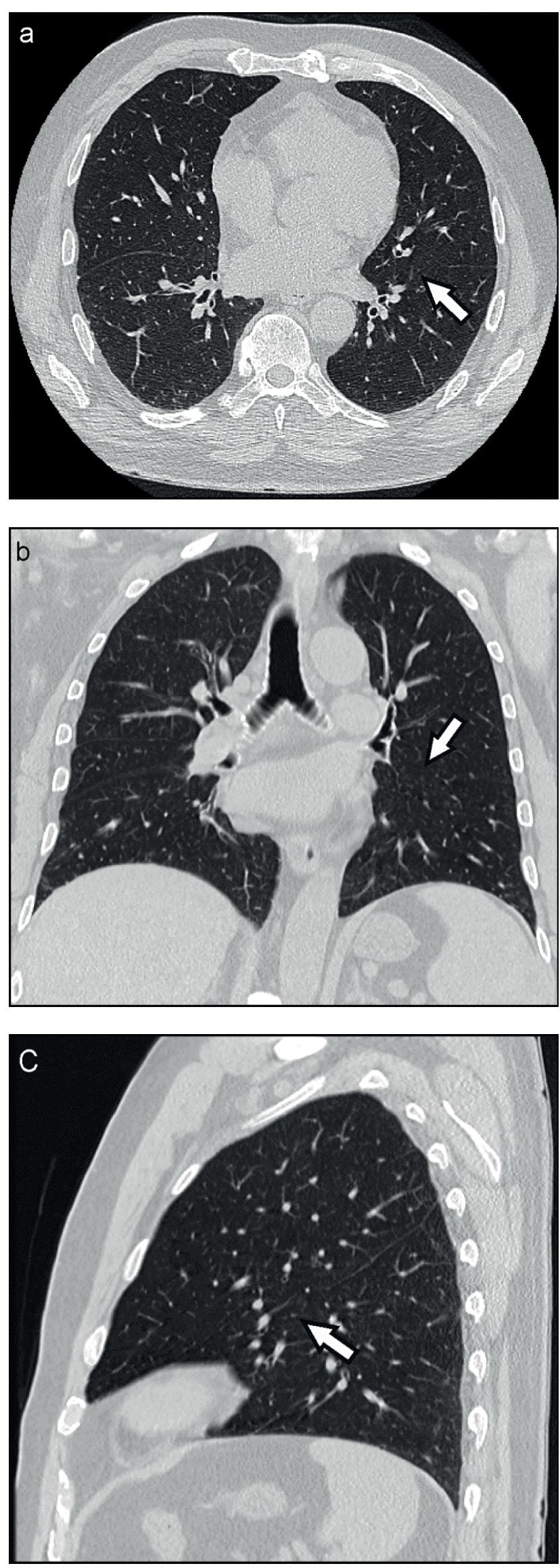

Fig. 1. a) Axial, b) coronal and c) sagittal HRCT reconstructions showing the incomplete left oblique fissure with parahilar disconnection (arrows). ing to the varying presence of vessels, including the situation when a fissure is simply missing. Data from various CT methods were mostly obtained from hundreds of patients ${ }^{1,12-23}$. Only Frija et al. ${ }^{12}$ used healthy volunteers. Hereafter, scans of patients indicated for this examination with no pathological finding on the chest CT (selected retrospectively) were used, as during CT examination irradiation cannot be avoided and it would not be ethical to perform such a study on healthy population. Pu et al. ${ }^{22}$ also included COPD patients. The prevalence of incomplete fissures ranged from $19.2 \%$ to $77 \%$ (mean 48.7 ), $17.4 \%$ to $87 \%$ (mean 55.4 ), and $48.3 \%$ to $89 \%$ (mean 69.8 ) for left oblique, right oblique, and horizontal fissures, respectively.

In two papers, the authors compared CT and perioperative findings of incomplete fissures. Kent et al. ${ }^{24}$ found a positive predictive value of CT compared with the perioperative findings of $100 \%, 75 \%$, and only $33 \%$ for right oblique fissures, left oblique fissures, and horizontal fissures, respectively, and their study consisted of 46 patients. Schieman et al. ${ }^{25}$ assessed the types of incomplete fissures on CT and during operations. They found that there was agreement between the type of incompleteness in CT and perioperative findings in $48 \%$ of cases; in the case of a totally complete fissure, the level of agreement was $94 \%$ in a total count of 61 patients.

Since the numbers of radiodiagnostic examinations are constantly growing and the search for incomplete fissures is time-consuming, automated computerized assessment ${ }^{26-28}$ offers a solution. A publication comparing the results of radiologists and an automatic system found no statistically significant difference in assessment ${ }^{19}$; in addition, the authors comparing CT and endobronchial measurement of collateral air flow ${ }^{29-31}$ concluded that the results correlated.

Detailed autopsies were mostly performed on small numbers of lungs and the prevalence ranged from $7.1 \%$ to $46.7 \%$ (mean $21.5 \%$ ), $5.6 \%$ to $39.3 \%$ (mean $24.6 \%$ ), and $7.8 \%$ to $74 \%$ (mean $40.4 \%$ ) for left oblique, right oblique, and horizontal fissures, respectively ${ }^{2,3,7,32-41}$. In this summary, we intentionally ignored a paper by Dogan et al. ${ }^{40}$ (included in Table 1) because they assessed the incompleteness of fissures in routine forensic autopsies, leaving large parts of the lung uninvestigated.

\section{CONCLUSION}

For better assurance before the implantation of an endobronchial valve in patients with COPD, the combination of CT and endobronchial methods is beneficial. In the case of lobectomy, a preoperative CT scan with a description of incomplete or even missing fissures can prevent perioperative as well as postoperative complications; however, the surgeon cannot totally depend on the information gained from CT. If a patient is indicated for surgical or endobronchial coil treatment, assessment of fissures is mandatory. The use of CT-based automated computerized assessment has proved to be very effective. 
Table 1. Frequencies of incomplete fissures on CT.

\begin{tabular}{|c|c|c|c|c|c|}
\hline $\begin{array}{l}\text { CT technique } \\
\text { (slice thickness/space between slices) }\end{array}$ & $\begin{array}{l}\text { Number } \\
\text { of patients }\end{array}$ & $\mathrm{LOF}$ & ROF & HF & Ref. \\
\hline $1.5 \mathrm{~mm} / 10 \mathrm{~mm}$ & 30 & $77 \%$ & $87 \%$ & - & 12 \\
\hline $10 \mathrm{~mm} / 10 \mathrm{~mm}$ & 50 & $52 \%$ & $64 \%$ & & 13 \\
\hline $1 \mathrm{~mm} / 10 \mathrm{~mm}$ & - & $50 \%$ & - & $83.1 \%$ & 1 \\
\hline $1 \mathrm{~mm} / 10 \mathrm{~mm}$ & 622 & $43 \%$ & $48 \%$ & $63 \%$ & 14 \\
\hline $1.5 \mathrm{~mm} / 6-10 \mathrm{~mm}$ & 144 & $59.7 \%$ & $62.5 \%$ & - & 15 \\
\hline $1 \mathrm{~mm} / 1 \mathrm{~mm}$ & 1000 & $19.2 \%$ & $17.4 \%$ & - & 16 \\
\hline $1.25 \mathrm{~mm} / 0.625 \mathrm{~mm}$ & 150 & $25.3 \%$ & $34 \%$ & $48.3 \%$ & 17 \\
\hline $1 \mathrm{~mm} / 1 \mathrm{~mm}$ & 387 & $48.3 \%$ & $69.7 \%$ & $86.9 \%$ & 18 \\
\hline $0.6-0.8 \mathrm{~mm} / 1 \mathrm{~mm}$ & 96 & $33 \%$ & $51 \%$ & & 19 \\
\hline 1 or $1.25 \mathrm{~mm} / 1 \mathrm{~mm}$ & 247 & $50 \%$ & $81 \%$ & $89 \%$ & 20 \\
\hline $0.625 \mathrm{~mm} / 0.625 \mathrm{~mm}$ or $1.25 \mathrm{~mm} / 0.625 \mathrm{~mm}$ & 250 & $24.4 \%$ & $35.2 \%$ & $74.4 \%$ & 21 \\
\hline $0.625 \mathrm{~mm} / 0.625 \mathrm{~mm}$ & 573 & $75 \%$ & $74 \%$ & $86 \%$ & 22 \\
\hline $1.25 \mathrm{~mm} / 1.25 \mathrm{~mm}$ & 208 & $46 \%$ & $41 \%$ & $62 \%$ & 23 \\
\hline
\end{tabular}

LOF - left oblique fissure, ROF - right oblique fissure, HF - horizontal fissure

Table 2. Frequencies of incomplete fissures obtained from autopsies.

\begin{tabular}{|c|c|c|c|c|}
\hline Pairs of lungs & $\mathrm{LOF}$ & ROF & $\mathrm{HF}$ & Ref. \\
\hline \multirow[t]{2}{*}{50} & $40 \%$ & $70 \%$ & $47 \%$ & 3 \\
\hline & $21 \%$ & & $31.5 \%$ & 33 \\
\hline 30 & $46.7 \%$ & $36.7 \%$ & $63.3 \%$ & 35 \\
\hline 51 & - & - & $7.84 \%$ & 36 \\
\hline 29 & $35.7 \%(+10.7 \% \mathrm{CM})$ & $39.3 \%(+7.1 \% \mathrm{CM})$ & $50 \%(+7.1 \% \mathrm{CM})$ & 37 \\
\hline 50 & $8 \%$ & $12 \%$ & $22 \%$ & 32 \\
\hline 30 & $7.1 \%(+3.6 \% \mathrm{CM})$ & - & $46.9 \%$ & 38 \\
\hline 40 left, 36 right & $2.5 \%$ & $5.55 \%$ & $25 \%$ & 34 \\
\hline 36 left, 46 right & $13.88 \%$ & $19.56 \%$ & $74 \%$ & 39 \\
\hline 65 left, 73 right & $15.06 \%$ & & $35.38 \%$ & 2 \\
\hline 40 & $31.8 \%$ & $22.7 \%$ & $63.6 \%$ & 7 \\
\hline 210 & $1 \%$ & $1.4 \%$ & $8.6 \%$ & 40 \\
\hline 40 & $35 \%$ & $15 \%$ & $50 \%$ & 41 \\
\hline
\end{tabular}

LOF - left oblique fissure, ROF - right oblique fissure, HF - horizontal fissure; CM - completely missing; * routine forensic autopsies

Table 3. Frequencies of incomplete fissures, comparison of CT and endobronchial measurement.

\begin{tabular}{|c|c|c|c|c|c|c|c|c|}
\hline \multirow[t]{2}{*}{ Patients } & \multicolumn{3}{|c|}{ CT } & \multirow{2}{*}{$\begin{array}{c}\text { Endobronchial } \\
\text { measurement }\end{array}$} & \multirow{2}{*}{$\begin{array}{c}\text { CT } \\
\text { sensitivity }\end{array}$} & \multirow{2}{*}{$\begin{array}{c}\mathrm{CT} \\
\text { specificity }\end{array}$} & \multirow{2}{*}{$\begin{array}{c}\mathrm{CT} \\
\text { accuracy }\end{array}$} & \multirow[t]{2}{*}{ Ref. } \\
\hline & LOF & ROF & $\mathrm{HF}$ & & & & & \\
\hline 25 & $65.2 \%$ & $84 \%$ & $92 \%$ & $57 \%$ & $95 \%$ & $44 \%$ & $73 \%$ & 30 \\
\hline 146 & & $63.6 \%$ & & $54.5 \%$ & $88.9 \%$ & $66.7 \%$ & $78.8 \%$ & 31 \\
\hline 21 & & $85.7 \%$ & & $52.4 \%$ & $93 \%$ & $33 \%$ & $76 \%$ & 29 \\
\hline
\end{tabular}

LOF - left oblique fissure, ROF - right oblique fissure, HF - horizontal fissure

Acknowledgement: This work was supported by the grant of Palacky University IGA-LF-2016-004.

Author contributions: $\mathrm{MH}, \mathrm{FC}$ : manuscript design, ZS: literature search, manuscript writing.

Conflict of interest statement: The authors declare that there are no conflicts of interest regarding the publication of this article.

\section{REFERENCES}

1. Otsuji H, Uchida H, Maeda M, Iwasaki S, Yoshiya K, Hatakeyama M, Ohishi H, lioka S, Narita N. Incomplete interlobar fissures: bronchovascular analysis with CT. Radiology 1993;187:541-6.

2. Bincy MG, Satheesha BN, Sapna M. Morphological variations of the lungs: a study conducted on Indian Cadavers. Anat Cell Biol 2014;47(4):253-8.

3. Raasch BN, Carsky EW, Lane EJ, O'Callaghan JP, Heitzman ER. Radiographic anatomy of the interlobar fissures: a study of 100 specimens. AJR Am J Roentgenol 1982;138:1043-9.

4. Sharma G, Vijayvergiya T. Anatomical variations in lobar pattern of lungs: Anatomical study and clinical significance. J Pharm Biomed Sci 2013;26(26)301-3. 
5. Igai H, Kamiyoshihara M, Kawatani N, Ibe T, Shimizu K. Thoracoscopic caudal left lower lobectomy in a patient with fused fissure. Asian J Endosc Surg 2014;7(4):342-4.

6. Taverne Y, Kleinrensink GJ, de Rooij P. Perioperative identification of an accessory fissure of the right lung. Case Rep pulmonol 2015; Vol. 2015, Article ID 954769.

7. Zareena SK. A study of morphology and variations of lungs in adults and foetus. IJOART 2014;3(4)150-7.

8. KosterTD, Slebos DJ. The fissure: interlobar collateral ventilation and implications for endoscopic therapy in emphysema. 2016;11:765-73.

9. Gompelmann D, Eberhardt R, Slebos DJ, Brown MS, Abtin F, Kim HJ, Holmes-Higgin D, Radhakrishnan S, Herth FJ, Goldin J. Diagnostic performance comparison of the Chartis System and high-resolution computerized tomography fissure analysis for planning endoscopic lung volume reduction. Respirology 2014;19(4):524-30.

10. Sciurba FC, Ernst A, Herth FJ, Strange C, Criner GJ, Marquette $\mathrm{CH}_{\text {, }}$ Kovitz KL, Chiacchierini RP, Goldin J, McLennan G; VENT Study Research Group. A randomized study of endobronchial valves for advanced emphysema. N Engl J Med 2010;363(13)1233-44.

11. Aljuri N, Freitag L. Validation and pilot clinical study of a new bronchoscopic method to measure collateral ventilation before endobronchial lung volume reduction. J Appl Physiol 2009;106(3):774-83.

12. Frija J, Schmid P, Katy M, Hacein-Bey L, Yana C, Laval-Jeantet M. Computed tomography of the pulmonary fissures: normal anatomy. J Comput Assist Tomogr 1982;6:1069-74.

13. Glazer HS, Anderson DJ, DiCroce JJ, Solomon SL, Wilson BS, Molina $\mathrm{PL}$, Sagel SS. Anatomy of the major fissure: evaluation with standard and thin-section CT. Radiology 1991;180:839-44.

14. Aziz A, Ashizawa K, Nagaoki K, Hayashi K. High resolution CT anatomy of the pulmonary fissures. J Thorac Imaging 2004;19:186-91.

15. Gülsün M, Ariyürek OM, Cömert RB, Karabulut N. Variability of the pulmonary oblique fissures presented by high-resolution computed tomography. Surg Radiol Anat 2006;28(3):293-9.

16. Mahmut $M$, Nishitani $H$. Evaluation of pulmonary lobe variations using multidetector row computed tomography. J Comput Assist Tomogr 2007;31:956-60.

17. Cronin P, Gross BH, Kelly AM, Patel S, Kazerooni EA, Carlos RC. Normal and accessory fissures of the lung: Evaluation with contiguous volumetric thin-section multidetector CT. Eur J Radiol 2010;75:e1-8.

18. Ozmen CA, Nazaroglu H, Bayrak AH, Senturk S, Akay HO. Evaluation of interlobar and accessory pulmonary fissures on 64-row MDCT. Clin Anat 2010;23(5)552-8.

19. Van Rikxoort EM, Goldin JG, Galperin-Aizenberg M, Abtin F, Kim HJ, Lu P, van Ginneken B, Shaw G, Brown MS. A method for the automatic quantification of the completeness of pulmonary fissures: evaluation in a database of subjects with severe emphysema. Eur Radiol 2012;22(2)302-9.

20. Koenigkam-Santos M, de Paula WD, Owsijewitsch M Wielpütz, MO Gompelmann D, Schlemmer HP, Kauczor HU, Heussel CP, Puderbach $M$. Incomplete pulmonary fissures evaluated by volumetric thinsection CT: semiquantitative evaluation for small fissure gaps identification, description of prevalence and severity of fissural defects. Eur J Radiol 2013;82(12)2365-70.

21. Heřmanová Z, Čtvrtlík F, Heřman M. Surface anatomy of the pulmonary fissures determined by high-resolution computed tomography. Clinical Anatomy 2012;25:835-43.

22. Pu J, Wang Z, Gu S, Fuhrman C, Leader JK, Meng X, Tedrow J, Sciurba FC. Pulmonary fissure integrity and collateral ventilation in COPD patients. PLoS One 2014;9(5): e96631. Published online.

23. Guan CS, Xu Y, Han D, Chen JH, WangXL, Ma DQ. Volumetric thinsection CT: evaluation of pulmonary interlobar fissures. Diagn Interv Radiol 2015;21(6)466-70.
24. Kent MS, Ridge C, O'Dell D, Lo P, Whyte R, Gangadharan SP. The accuracy of computed tomography to predict completeness of pulmonary fissures. A prospective study. Ann Am Thorac Soc 2015;12(5):696-700.

25. Schieman C, MacGregor JH, Kelly E, Graham A, McFadden SP, Gelfand G, Grondin SC. Can preoperative computed tomography of the chest predict completeness of the major pulmonary fissure at surgery? Can J Surg 2011;54(4):252-6.

26. Yu M, Liu H, Gong J, Jin R, Han P, Song E. Automatic segmentation of pulmonary fissures in computed tomography images using 3D surface features. J Digit Imaging 2014;27(1)58-67.

27. Lai J, Wei Q. Automatic lung fields segmentation in CT scans using morphological operation and anatomical information. Biomed Mater Eng 2014;24(1)335-40.

28. Ross JC, Kindlmann GL, Okajima Y, Hatabu H, Díaz AA, Silverman EK, Washko GR, Dy J, San José Estépar R. Pulmonary lobe segmentation based on ridge surface sampling and shape model fitting. Med Phys 2013;40(12)121903.

29. Diso D, Anile M, Carillo C, Ruberto F, Patella M, Russo E, Fraioli F De Giacomo T, Mantovani S, Rendina E, Venuta F. Correlation between collateral ventilation and interlobar lung fissures. Respiration 2014;88(4):315-9.

30. Reymond E, Jankowski A, Pison C, Bosson JL, Prieur M Aniwidyaningsih W, Ferretti GR. Prediction of lobar collateral ventilation in 25 patients with severe emphysema by fissure analysis with CT. AJR Am J Roentgenol 2013;201(4):571-5.

31. Schuhmann M, Raffy $P$, Yin Y, Gompelmann D, Oguz I, Eberhardt R, Hornberg D, Heussel CP, Wood S, Herth FJ. Computed tomography predictors of response to endobronchial valve lung reduction treatment. Comparison with Chartis. Am J Respir Crit Care Med 2015;191(7):767-74.

32. Nene AR, Gajendra KS, Sarma MVR. Lung lobes and fissures: a morphological study. International Journal of Experimental and Clinical Anatomy 2011;5:30-8.

33. Lukose R, Paul S, Sunitha DM, Daniel M, Abraham SM, Alex ME. Morphology of the lungs: variations in the lobes and fissures. Biomedicine 1999;19:227-37.

34. Quadros LS, Palanichamy R, D'Souza S. Variations in the lobes and fissures of lungs - a study in South Indian lung specimens. Eur J Anat 2014;18(1):16-20.

35. Meenakshi S, Manjunath KY, Balasubramanyam V. Morphological variations of the lung fissures and lobes. Indian J Chest Dis Allied Sci 2004;46:179-82.

36. Gesase AP. The morphological features of major and accessory fissures observed in different lung specimens. Morphologie 2006;90:26-32.

37. Prakash, Bhardwaj AK, Shashirekha M, Suma HY, Krishna GG, Singh G. Lung morphology: a cadaver study in Indian population. Ital J Anat Embryol 2010;115:23-40.

38. Murlimanju BV, Prabhu LV, Shilpa K, Pai MM, Kumar CG, Rai A, Prashanth KU. Pulmonary fissures and lobes: a cadaveric study with emphasis on surgical and radiological implications. Clin Ter 2012;163:9-13.

39. Ghosh E, Basu R, Dhur A, Roy A, Roy H, Biswas A. Variations of fissures and lobes in human lungs - a multicentric cadaveric study from West Bengal, India. International Journal of Anatomy, Radiology and Surgery 2013;2(1):5-8.

40. Unver Dogan N, Uysal II, Demirci S, Dogan KH, Kolcu G. Major anatomic variations of pulmonary fissures and lobes on postmortem examination. Acta Clin Croat 2015;54(2):201-7.

41. Mamatha Y, Murthy ChK, Prakash BS. Study of morphological variations of fissures and lobes of lung. Int J Anat Res 2016;4(1):1874-7. 